\title{
EFICIÊNCIA NO USO DE ÁGUA: BRASIL E UM PANORAMA INTERNACIONAL ${ }^{1}$
}

Jaqueline C. Visentin²

Leonardo Szigethy ${ }^{3}$

\section{SINOPSE}

Muito se fala sobre o papel das tecnologias no uso dos recursos naturais de forma eficiente e, com a implementação da Agenda 2030, o tema ganhou ainda mais relevância. Este texto visa apresentar um panorama da eficiência no uso de água pelo mundo, reunindo informaçôes através de uma comparação internacional utilizando o indicador "Alterações na Eficiência do Uso da Água” do Objetivo de Desenvolvimento Sustentável (ODS) 6 (meta 6.4). Espera-se que este possa ser um primeiro passo para estudos futuros que avaliem a possibilidade de implementação de tecnologias eficientes no uso dos recursos hídricos baseadas em experiências internacionais.

Palavras-chave: Agenda 2030; ODS; eficiência; recursos hídricos.

\section{INTRODUÇÃO}

As negociações da Agenda 2030, concluídas em setembro de 2015, culminaram em dezessete Objetivos de Desenvolvimento Sustentável (ODS) e 169 metas correspondentes. A sua implementação ocorre desde 2016, com prazo de conclusão até 2030.

Entre os ODS, o de número 6, Água Limpa e Saneamento, é composto por oito metas que visam "assegurar a disponibilidade e gestáo sustentável da água e saneamento para todas e todos". Nesse contexto, destaca-se a meta 6.4: "até 2030, aumentar substancialmente a eficiência do uso da água em todos os setores, assegurando retiradas sustentáveis e o abastecimento de água doce para reduzir substancialmente o número de pessoas que sofrem com a escassez" (ANA, 2019a, p. 32).

Entre os indicadores de monitoramento dessa meta, destaca-se o 6.4.1: Alteraçôes na Eficiência do Uso da Água, que é mensurado pela relação entre o valor adicionado bruto (VAB), a preços constantes, e o volume da demanda hídrica de retirada, para agropecuária, indústrias e serviços. O movimento desse indicador ao longo do tempo pode refletir mudanças tecnológicas setoriais, nos ciclos econômicos ou mesmo na composição de bens e serviços produzidos e demandados pelo mercado, por exemplo.

Muito se fala sobre o papel das tecnologias no uso dos recursos naturais e a sua capacidade de produzir uma dissociação entre a produção econômica e o uso desses recursos de forma mais eficiente. Este artigo dá um passo inicial na investigação do tema, reunindo informaçóes para estudos futuros que avaliem se o emprego de tecnologias eficientes no uso dos recursos hídricos tem contribuído para a melhoria do indicador 6.4.1 e, consequentemente, para o alcance da meta 6.4 do ODS 6.

1. DOI: http://dx.doi.org/10.38116/radar64art4.

2. Pesquisadora do Subprograma de Pesquisa para o Desenvolvimento Nacional (PNPD) na Diretoria de Estudos e Políticas Setoriais de Inovação e Infraestrutura (Diset) do Ipea. E-mail: <coelhovisentin@gmail.com>.

3. Pesquisador do PNPD na Diset/lpea. E-mail: <leonardo.szigethy@ipea.gov.br>. 


\section{METODOLOGIA DE CÁLCULO DA DEMANDA HÍDRICA}

No cálculo do indicador 6.4.1: Alteraçôes na Eficiência do Uso da Água, a variável utilizada para se medir a demanda hídrica de retirada difere entre as três atividades econômicas.

Para a agropecuária, é considerada a captação direta de água para o uso em irrigação, pecuária e aquicultura. Isso inclui a captação em corpos hídricos superficiais e subterrâneos, o uso direto de águas de drenagem agrícola, águas residuais (tratadas) e dessalinizadas.

Para as indústrias, os mesmos tipos de corpos hídricos são considerados, bem como o uso de água dessalinizada e de reuso; inclui a captação própria para refrigeração de usinas termelétricas, mas exclui a energia hidrelétrica. No entanto, o uso da água para esse setor deve incluir perdas por evaporação de lagos artificiais, que são usados em hidroelétricas.

No caso dos serviços, em vez de se computar a captação direta de água, o volume da demanda hídrica se refere à água advinda das atividades de saneamento. Assim, o cálculo do indicador se dá entre o VAB do setor de serviços e o total de água retirada pela rede de distribuição pública. Portanto, essa estimativa não considera somente o volume de água direcionada ao setor, mas também às famílias.

\section{EFICIÊNCIA NO USO DA ÁGUA NO BRASIL}

Em 2019, a Agência Nacional de Águas (ANA) publicou o relatório ODS 6 no Brasil: visão da ANA sobre os indicadores, no qual apresenta a sua contribuição ao processo de monitoramento das oito metas do ODS 6 no Brasil. ${ }^{4}$ Entre as evidências encontradas, destaca-se que, de 2010 a 2015, houve crescimento de 2\% na eficiência do uso de água, variando de $\mathrm{R} \$ 74,7 / \mathrm{m}^{3}$, em 2010, a $\mathrm{R} \$ 76,4 / \mathrm{m}^{3}, 5$ em 2015 (ANA, 2019a).

Para avaliar o indicador de eficiência nos diferentes setores econômicos, antes é importante conhecer a relevância de cada setor no uso de água e na geração de valor adicionado. A partir dos resultados das segundas Contas Econômicas Ambientais da Água (CEAAs) do Brasil, verifica-se que a principal atividade responsável pela captação direta de Água Azul para fins consuntivos - volume de água captado que é consumido no processo produtivo de modo a não retornar ao corpo hídrico (IBGE e ANA, 2020) -, em 2017, foi a agropecuária (56\%), seguida por serviços $(30 \%)$ e indústrias (14\%).

Com relação ao valor adicionado, a partir das informaçóes sobre as Contas Nacionais divulgadas pelo Instituto Brasileiro de Geografia e Estatística (IBGE), verifica-se que a participação dessas atividades se altera, quando comparada à participaçáo na captação direta de Água Azul. Isto é, os serviços passam a ocupar o primeiro lugar, sendo responsáveis por $74 \%$ do VAB de 2017, seguidos das indústrias, 21\%, e da agropecuária, 5\% (IBGE, 2019).

No que se refere aos resultados sobre a eficiência no uso de água, entre 2010 e 2015, verificou-se que a agropecuária manteve-se estável, com média de eficiência de $\mathrm{R} \$ 2,1 / \mathrm{m}^{3}$, apresentando pequenas variaçóes na demanda hídrica de retirada e no valor adicionado. Esses valores aumentaram nos serviços, com média de $\mathrm{R} \$$ $222 / \mathrm{m}^{3}$ e um aumento de $11,74 \%$ da eficiência no período, influenciados pelo aumento no valor adicionado. Nas indústrias, por sua vez, o resultado foi de $\mathrm{R} \$ 93,8 / \mathrm{m}^{3}$ e queda de 22,07\% no período, em decorrência do simultâneo aumento da demanda hídrica de retirada e do menor valor adicionado.

4. Entre os outros materiais sobre os ODS no Brasil, destacam-se a Agenda 2030 - metas nacionais dos Objetivos de Desenvolvimento Sustentável e o Caderno ODS 6, ambos produzidos pelo Ipea.

5. Valor correspondente a US\$25,7/m³ (FAO, 2018). 


\section{EFICIÊNCIA NO USO DA ÁGUA NO MUNDO}

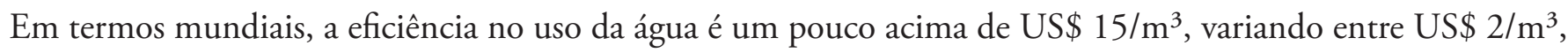
em países cujas economias são altamente dependentes da agricultura, e US $\$ 1 \mathrm{mil} / \mathrm{m}^{3}$, em economias altamente industrializadas ou baseadas em serviços (FAO, 2018).

$\mathrm{Na}$ comparação entre países, é interessante considerar aqueles cujas estruturas produtivas, padrão de demanda de água e/ou tamanho da economia sejam parecidos. Assim, foram selecionados os países que compóem o G20, ${ }^{6}$ pois representam cerca de $80 \%$ da produção econômica mundial, dois terços da populaçáo global e três quartos do comércio internacional. ${ }^{7}$

Entre os países do grupo, nove apresentaram maior eficiência no uso da água do que o Brasil (US\$21/ $\left.\mathrm{m}^{3}\right)$,

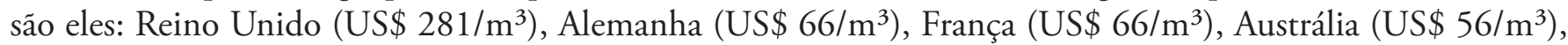

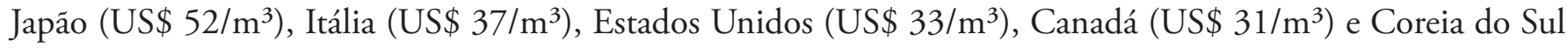
(US\$ $\left.26 / \mathrm{m}^{3}\right)$.

No entanto, esse resultado reflete uma série de características próprias de cada região, tais como o cultivo de diferentes culturas agrícolas, o desenvolvimento de diferentes atividades industriais, distintos padrôes pluviométricos etc. Uma maneira de reduzir essa heterogeneidade é fazer a comparação internacional por atividade econômica. ${ }^{8}$

Essas diferenças refletem as características distintas das atividades econômicas com relação ao uso de água. Por exemplo, enquanto o setor agropecuário tende a ser o principal demandante de água, ele se caracteriza pelo baixo valor adicionado, quando comparado aos serviços e às indústrias. Por isso, a comparaçáo do indicador de eficiência no uso da água entre atividades econômicas deve ser feita com cautela, considerando-se a natureza distinta de cada atividade.

\section{TABELA 1}

Comparação internacional: eficiência no uso de água na agropecuária, nas indústrias e nos serviços (Em US\$/ $/ \mathrm{m}^{3}$ )

\begin{tabular}{|c|c|c|c|c|}
\hline Países do G20 & Agropecuária & Indústrias & Serviços & Total \\
\hline África do Sul & 0,2 & 61 & 32 & 15 \\
\hline Alemanha & 1,1 & 24 & 337 & 66 \\
\hline Arábia Saudita & 0,3 & 412 & 75 & 19 \\
\hline Argentina & 0,2 & 36 & 53 & 12 \\
\hline Austrália & 0,3 & 123 & 187 & 56 \\
\hline Brasil & 0,3 & 35 & 54 & 21 \\
\hline Canadá & 0,4 & 12 & 148 & 31 \\
\hline China & 1,7 & 32 & 67 & 17 \\
\hline Coreia do Sul & 1,2 & 63 & 54 & 26 \\
\hline
\end{tabular}

6. O G20 é composto por dezenove países e pela União Europeia. Refere-se a um fórum de cooperação econômica internacional que reúne líderes de países desenvolvidos e em desenvolvimento de todos os continentes. A União Europeia não foi selecionada já que não é um país, mas, sim, um bloco econômico, 0 que poderia causar distorções na comparação.

7. Disponível em: <https://g20.org/en/about/Pages/whatis.aspx>. Acesso em: maio 2020.

8. Para a análise dos dados setoriais, utilizou-se como base de dados a tabela disponível em FAO (2018). Nessa tabela, há dados para 168 países; no entanto, não é possível identificar o ano de referência dessas informações. 


\begin{tabular}{lcccc} 
(Continuação) & Agropecuária & Indústrias & Serviços & Total \\
\hline Países do G20 & 0,4 & 14 & 206 & $\mathbf{3 3}$ \\
\hline Estados Unidos & 1,8 & 20 & 285 & $\mathbf{6 6}$ \\
França & 0,3 & 29 & 14 & $\mathbf{2}$ \\
Índia & 0,2 & 24 & 12 & $\mathbf{3}$ \\
Indonésia & 1,0 & 28 & 131 & $\mathbf{3 7}$ \\
Itália & 0,6 & 100 & 52 & $\mathbf{5 2}$ \\
Japão & 0,2 & 48 & 313 & $\mathbf{1 2}$ \\
México & 0,7 & 435 & $\mathbf{3 2}$ & $\mathbf{2 8 1}$ \\
Reino Unido & 0,1 & $\mathbf{3 2}$ & $\mathbf{1 1}$ \\
Rússia & 0,5 & 24 & $\mathbf{8}$ \\
Turquia & & 36 & \\
\hline
\end{tabular}

Fonte: FAO (2018).

Elaboração dos autores.

Com relação à agropecuária, o resultado do Brasil é de US\$ $0,3 / \mathrm{m}^{3}$, que é igual ao da Austrália e semelhante ao do México (US\$ 0,2/ $\mathrm{m}^{3}$ ). Dez países apresentaram indicadores maiores do que os do Brasil. Sáo eles: França, China, Coreia do Sul, Alemanha, Itália, Reino Unido, Japão, Turquia, Estados Unidos e Canadá.

No setor industrial, oito países apresentaram indicadores maiores do que os do Brasil (US\$ 35/m³). São

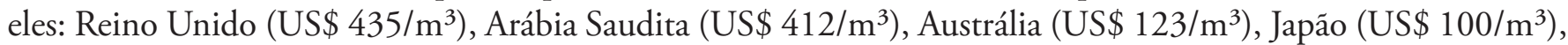

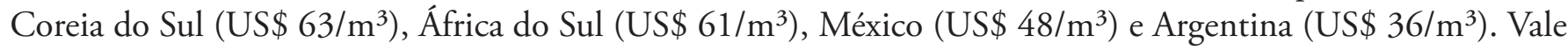
mencionar que o Brasil se mostrou parecido com a China (US\$32/ $\mathrm{m}^{3}$ ).

Com relação aos serviços, dez países apresentaram indicadores maiores do que os do Brasil $\left(\mathrm{US} \$ 54 / \mathrm{m}^{3}\right)$.

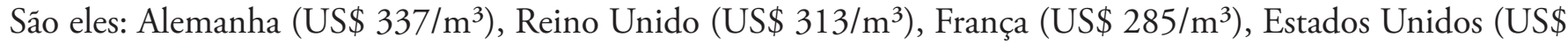

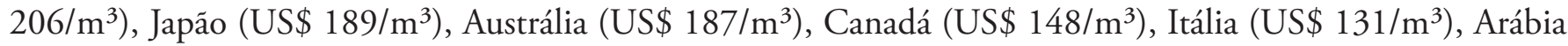

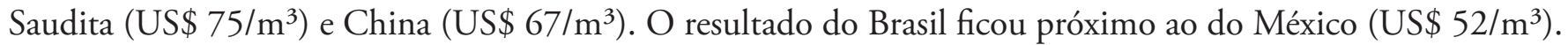

Ainda em relação ao setor de serviços (que engloba as atividades de saneamento), é importante destacar que o Índice de Perda na Distribuição (IPD) no Brasil foi de 38,5\% em 2018, variando entre 55,5\% na região Norte e 34,4\% no Sudeste. Isto é, 38,5\% do volume de água distribuído via sistema de saneamento foi perdido devido a vazamentos, falhas nos sistemas de medição ou ligaçóes clandestinas.

\section{CONSIDERAÇÕES FINAIS}

A eficiência no uso de água da agropecuária no Brasil se manteve estável entre 2010 e 2015. Apesar de a maior parcela da captação direta de água ser proveniente das chuvas, a comparaçáo internacional parece indicar que há espaço para melhorar esse indicador.

Além de as atividades agropecuárias de nove países do G20 serem mais eficientes, um indício adicional da possibilidade de maior eficiência no uso da água pela agropecuária brasileira é o fato de a China apresentar um indicador de eficiência 5,7 vezes maior do que o do Brasil. Note-se que a China é o maior produtor de arroz no mundo, a principal cultura agrícola responsável pelo uso de água no Brasil (ANA, 2019b). Assim, a introdução e difusão de tecnologias podem desempenhar um importante papel no aumento da eficiência.

9. Disponível em: <http://www.fao.org/faostat/en/\#home>. Acesso em: maio 2020. 
Com relação à indústria, a própria queda na eficiência do uso de água e o crescimento do volume de água demandado no Brasil entre 2010 e 2015 indicam uma possibilidade de melhoria. As experiências de países como o Reino Unido, a Arábia Saudita, a Austrália, o Japão, a Coreia do Sul e a África do Sul podem auxiliar nesse sentido.

A eficiência no uso de água por parte dos serviços no Brasil cresceu entre 2010 e 2015 . No entanto, diferenças consideráveis em relação a alguns dos países mais eficientes do G20 indicam a possibilidade de uma melhoria importante no país. Esse dado, associado ao IPD no Brasil, reforça a necessidade de investimentos em saneamento.

Por fim, com a identificação dos países cuja eficiência setorial no uso de água é maior que a do Brasil, abrese o caminho para a investigação das causas dessas diferenças e a possibilidade de avaliação da viabilidade do emprego de novas tecnologias de uso eficiente de água.

\section{REFERÊNCIAS}

ANA - AGÊNCIA NACIONAL DE ÁGUAS. ODS 6 no Brasil: visão da ANA sobre os indicadores. Brasília: ANA, 2019a. Disponível em: <https://bit.ly/32XVABd>.

Manual de usos consuntivos da água no Brasil. Brasília: ANA, 2019b. Disponível em: <https://bit.ly/3fdcoZR>.

FAO - FOOD AND AGRICULTURE ORGANIZATION OF THE UNITED NATIONS. Progress on water-use efficiency - global baseline for SDG indicator 6.4.1. Rome: FAO, 24 Aug. 2018. 56 p. Disponível em: <https://bit. ly/36P7cHH>.

IBGE - INSTITUTO BRASILEIRO DE GEOGRAFIA E ESTATÍSTICA. Sistema de contas nacionais - Brasil 2017. Rio de Janeiro: IBGE, 2019. 20 p. Disponível em: <https://bit.ly/3nKBHpf>.

IBGE - INSTITUTO BRASILEIRO DE GEOGRAFIA E ESTATÍSTICA; ANA - AGÊNCIA NACIONAL DE ÁGUAS. Contas econômicas ambientais da água - Brasil 2013-2017. Rio de Janeiro: IBGE, 2020. (Contas Nacionais, n. 72). Disponível em: <https://bit.ly/2IHq2IV>. 